\title{
Long term remission of portopulmonary hypertension with liver transplantation in a patient with cirrhosis associated to autoimmune hepatitis
}

\author{
Alejandro Costaguta ${ }^{(\mathbb{D}}$, María G, Gutiérrez ${ }^{a}$, Guillermo Costaguta ${ }^{a}$ (D), Natalia Reyes ${ }^{a}$, Lisandro Bitetti ${ }^{a}$
}

\begin{abstract}
Portopulmonary hypertension is an uncommon complication of portal hypertension, running a progressive course with a negative prognosis. Reports in pediatric patients are scarce with short follow up. We describe the case of decompensated cirrhosis who developed PoPH and resolved with liver transplantation, remaining asymptomatic after ten years of follow up.

Key words: pulmonary hypertension, portal hypertension, liver transplantation, child.
\end{abstract}

http: / / dx.doi.org/10.5546/ aap.2022.eng.e17

To cite: Costaguta A, Gutiérrez MG, Costaguta G, Reyes N, Biletti L. Long term remission of portopulmonary hypertension with liver transplantation in a patient with cirrhosis associated to autoimmune hepatitis. Arch Argent Pediatr 2022;120(1):e17-e20.

\section{INTRODUCTION}

Portopulmonary hypertension $(\mathrm{PoPH})$ is a feared consequence of portal hypertension $(\mathrm{PH})$ described in both cirrhotic and non-cirrhotic patients. It usually evolves silently for years, despite advanced disease. ${ }^{1}$ The disorder runs a progressive course from vasoconstriction to hypertrophy of small pulmonary arteries leading to right-sided cardiac failure. ${ }^{2,3}$ In untreated adult patients the mean survival time has been estimated in 6 months from diagnosis, and 5-year survival of $40 \%$ to $70 \%$ among those receiving vasodilators and liver transplantation. Even though mild to moderate cases of PoPH may show good responses with liver transplantation; optimal timing and patient characteristics for such an intervention have not been clearly defined

a. Unidad de Hígado y Trasplante Hepático.

Sanatorio de Niños. Rosario, Santa Fe, Argentina.

E-mail address:

Guillermo Costaguta: gcostaguta5@gmail.com

Funding: None.

Conflict of interest: None.

Received: 7-25-2020

Accepted: 7-7-2021 for the pediatric population, and records of such patients are scarce and with little data on long term follow-up. ${ }^{4}$

We report an adolescent girl who presented to consultation with decompensated autoimmune cirrhosis and $\mathrm{PoPH}$ which responded to vasodilators and liver transplantation, remaining on stable remission after 10 years.

\section{CASE REPORT}

A 12 years old girl was referred to us because of painful abdominal distension, jaundice and dark urine five days prior. She had a previous history of an appendectomy at 8 years, with no further complications. On admission she looked ill, her blood pressure was $110 / 80 \mathrm{mmHg}$, with a heart rate of $124 \mathrm{bpm}$, and a hyperphonetic and fixedly-split second cardiac sound. The abdomen was painful and distended, with shift dullness and recent development of an umbilical hernia. She also evidenced peripheral edema, but no other pathologic findings.

Biochemical tests revealed a severe hepatic disease (Table 1). Chest $X$-rays showed

TABLE 1. Biochemical profile on admission and at the time of enrollment in the liver transplant list

\begin{tabular}{lcc}
\hline & Admission & Waiting list \\
\hline Hematocrit (\%) & 37.6 & 32 \\
Hemoglobin $(\mathrm{g} / \mathrm{dl})$ & 12.7 & 10.5 \\
WBC $\left(/ \mathrm{mm}^{3}\right)$ & 9100 & 8700 \\
Platelets $\left(/ \mathrm{mm}^{3}\right)$ & 105,000 & 92,000 \\
BUN $(\mathrm{mg} / \mathrm{dl})$ & 12 & 16 \\
Na $(\mathrm{mEq} / \mathrm{l})$ & 138 & 131 \\
AST $(\mathrm{IU} / \mathrm{L})$ & 328 & 292 \\
ALT $(\mathrm{aIU} / \mathrm{L})$ & 279 & 256 \\
Total bilirubin $(\mathrm{mg} / \mathrm{dl})$ & 3.8 & 3.9 \\
Direct bilirubin $(\mathrm{mg} / \mathrm{dl})$ & 1.4 & 1.6 \\
Albumin $(\mathrm{g} / \mathrm{dl})$ & 2.4 & 2.2 \\
INR & 2.6 & 2.1 \\
\hline
\end{tabular}

WBC: White blood cells.

BUN: Blood urea nitrogen.

AST: Aspartate aminotranspherase.

ALT: Alanine aminotranspherase.

INR: International normalized ratio. 
cardiomegaly at the expense of right ventricle with a prominent pulmonary arch and perihilar congestion. At abdominal ultrasound the liver was small and heterogeneous, with normal Doppler signal, and severe ascites. On cardiac ultrasound, moderate right atrioventricular dilation with paradoxical septal motion and mild pericardial effusion was evident. Calculated pulmonary artery systolic pressure (PASP) was $87 \mathrm{mmHg}$ (normal values 18 to $25 \mathrm{mmHg}$ ). The abdominal paracentesis yielded $2200 \mathrm{PMN} / \mathrm{ml}$, and E. coli was isolated from peritoneal fluid. The patient was treated with cefotaxime, furosemide, spironolactone, and IV albumin. Diagnosis of type 1 autoimmune hepatitis was made based on serum IgG level of $2896 \mathrm{mg} / \mathrm{dl}$ and anti-smooth muscle antibodies titer of $1 / 640$. Oral prednisone (40 mg q.d.) was started, with sildenafil $3 \mathrm{mg} /$ $\mathrm{kg} / \mathrm{d}$ aimed to lower the pulmonary pressure. A new echocardiogram done 15 days after showed good response, with a new PSAP calculated on $50 \mathrm{mmHg}$. A cardiac catheterization was carriedout, revealing a mean pulmonary artery pressure (mPAP) of $36 \mathrm{mmHg}$ (normal values $<25 \mathrm{mmHg}$ ), with a pulmonary vascular resistance (PVR) in 573 dyn.sec.cm ${ }^{-5}(7 \mathrm{uW})$ (normal values $<3 \mathrm{uW}$ ), and a wedge pressure of $12 \mathrm{mmHg}$, consistent with the diagnosis of moderate precapilary pulmonary hypertension (PH).

Despite initial clinical response, the patient decompensated 10 days later with recurrence of sterile ascites needing constant support in the ICU. She was placed on the waiting list with a MELD score of 24 points, and a liver transplantation was done $24 \mathrm{~h}$ later with a full deceased donation ABO-identic graft. A
mPAP between 36 and $45 \mathrm{mmHg}$ was recorded through Swan-Ganz catheter during the operative procedure, with good right ventricular function. Two hours after return to ICU, mPAP raised to $54 \mathrm{mmHg}$ (more than $50 \%$ the systemic pressure) not responding to conservative measures. Therefore, inhaled nitric oxide was started at $20 \mathrm{ppm}$, augmenting to $40 \mathrm{ppm} 7$ hours later, after $\mathrm{mPAP}$ reached a peak of $65 \mathrm{mmHg}$. During the following hours MPAP values stabilized around $40 \mathrm{mmHg}$, and nitric oxide withdrawal was achieved after 72 hours with values of mPAP of $35 \mathrm{mmHg}$ (Figure 1). Initial immunosuppression consisted of methylprednisolone and basiliximab, adding tacrolimus at $4^{\text {th }}$ postoperative day. A week later, a brief episode of seizures was treated with anticonvulsants and diagnosed as a posterior reversible encephalopathy syndrome attributed to tacrolimus toxicity which prompted its temporary suspension. At $20^{\text {th }}$ postoperative day the girl was sent home on prednisone $(2 \mathrm{mg} / \mathrm{kg} / \mathrm{d})$, tacrolimus (trough level of $8 \mathrm{ng} / \mathrm{ml}$ ), and mycophenolate mofetil $\left(600 \mathrm{mg} / \mathrm{m}^{2}\right)$. Sildenafil was also maintained at 0.5 to $1 \mathrm{mg} / \mathrm{kg} / \mathrm{d}$. During the following months, calculated PASP through echocardiography was around 40 and $50 \mathrm{mmHg}$ and the patient was allowed to return to its previous activities with almost no restriction. In an attempt to normalize pulmonary pressures, bosentan was introduced but had to be interrupted because of a rise in liver enzymes (ALT $240 \mathrm{IU} / \mathrm{L}$, AST $198 \mathrm{IU} / \mathrm{L}$ ), with normalization after its withdrawal.

Over the following years she made an uneventful recovery, finishing school and keeping a normal young adult life. Sildenafil was

FIGURE 1. Mean pulmonary artery pressure values observed during perioperative time in the present case.

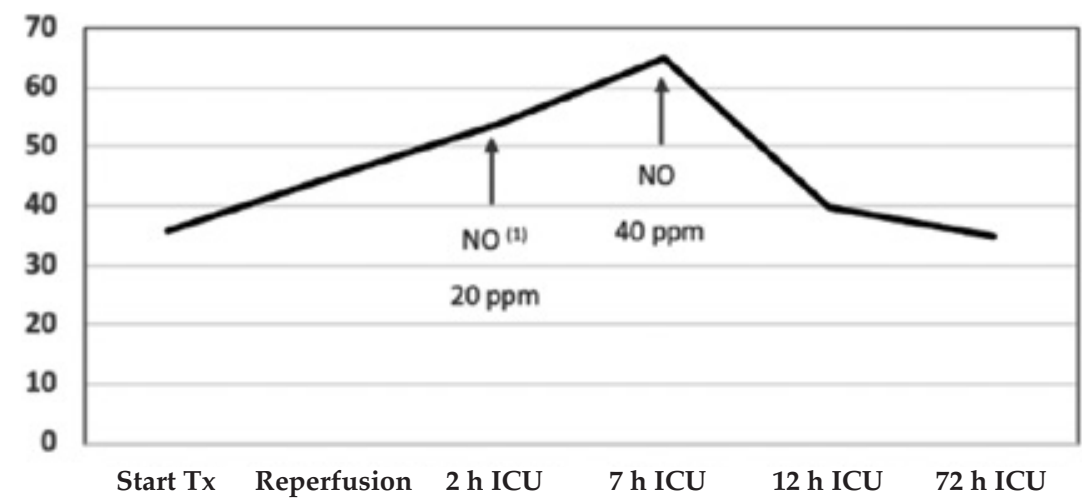

(1) NO: Nitric oxide; Tx: transplant; ICU: Intensive Care Unit. 
suspended 2 years later after confirming stable normal values of pulmonary pressure through repeated echocardiograms. She is currently off all medication except for daily tacrolimus (trough levels of 3-5 ng/ml), at ten years after transplantation.

\section{DISCUSSION}

PoPH is a serious condition in which a pulmonary vasculopathy develops as a consequence of portosystemic shunt of the splanchnic blood either in cirrhotic or noncirrhotic patients. It begins with a potentially reversible phase of vasoconstriction to a one with arterial remodeling, with intimal proliferation and medial hypertrophy that is probably irreversible. Since appropriate treatment could reverse progression, timely diagnosis is mandatory; otherwise, they are faced with a negative shortterm prognosis. ${ }^{4}$

Opportune diagnosis, however, is hampered for two main reasons: first, $\mathrm{PoPH}$ is infrequent, with a prevalence of $5 \%$ among adult cirrhotic patients and less than $1 \%$ in children; and second, PoPH can go unnoticed for months to years because its oligosymptomatic nature. ${ }^{5}$ Furthermore, the presence of $\mathrm{PoPH}$ does not correlate neither with the severity of the liver disease nor with the degree of portal hypertension. ${ }^{6}$ Therefore, awareness of this entity and methodic screening of patients at risk are obligatory.

PoPH diagnosis relays on the demonstration of pulmonary hypertension in a patient with portosystemic shunt of blood. It can be suspected through Doppler echocardiography with a calculated PASP over $50 \mathrm{mmHg}$ and confirmed with a cardiac catheterization showing a rising $\mathrm{mPAP}$ over $25 \mathrm{mmHg}$, a resistance higher than 3 Woods units (240 Dyn.sec. $\mathrm{cm}^{-5}$ ), and a pulmonary wedge pressure lower than $15 \mathrm{mmHg} .{ }^{1,45}$ Initial therapeutic approach usually involves vasodilators and endothelin-receptor antagonists, but definitive resolution can only be achieved by removing the cause, which in cirrhotic patients will most likely imply a liver transplantation. However, careful selection of both candidate and opportunity needs to be judiciously weighted., ${ }^{7,8}$

Formerly considered a contraindication to liver transplantation, a better knowledge of the disease, and the good results reported in isolated cases have turned PoPH into a possible indication for liver transplantation. PoPH can be classified as mild (25-34 $\mathrm{mmHg})$, moderate (35-44 $\mathrm{mmHg}$ ) or severe $(>45 \mathrm{mmHg}$ ) based on values of mPAP obtained during right heart catheterization. ${ }^{5}$ Patients with good response to vasodilators, with mild or moderate pulmonary hypertension are considered good candidates for liver transplantation and should be placed in the waiting list with special considerations in their MELD/PELD score. ${ }^{4,7,9}$ A preserved right ventricular function measured by transthoracic Doppler ultrasound could contribute in making the decision in difficult cases. ${ }^{10}$

Reversal of PoPH with vasodilators and liver transplantation has been reported previously ${ }^{11,12}$, however, the largest pediatric series consists of only 14 pediatric. In this review, only 9 had cirrhosis and all related to biliary atresia, a very different scenario than post-necrotic cirrhosis as in our case. ${ }^{4}$ Two of those patients died early, leaving only 7 children reported to date with PoPH remission after liver transplantation, and only 3 of them had a follow up of 2 years or more.

Our patient experimented a rapid improvement and favorable outcome after liver transplantation returning to a normal life in a few months after surgery. Two years after transplantation she could be taken off medication (sildenafil) and PASP values remain within normal range.

In summary, our case illustrates a favorable outcome of PoPH associated to post-necrotic cirrhosis with long term remission after ten years of follow-up, highlighting the value of liver transplantation for this indication in carefully selected patients.

\section{REFERENCES}

1. Rodríguez-Roisin R, Krowka M, Hervé P, Fallon M, et al. Pulmonary-Hepatic vascular disorders (PHD). Eur Respir J. 2004; 24(5):861-80.

2. Cartin-Ceba R, Krowka M. Portopulmonary hypertension. In: Lee S, Moreau R, (eds). Cirrhosis. A practical guide to management. WestSussex:John Wiley \&Sons;2015.Págs.21224.

3. Swanson K, Krowka M. Pulmonary complications associated with portal hypertension. In Sanyal A, Shah V, (eds). Portal Hypertension. Pathobiology, evaluation, and treatment. New Jersey: Humana Press; 2010.Págs.455-68.

4. Ecochard-Dugelay E, Lambert V, Schleich J, Duché M, et al. Portopulmonary hypertension in liver disease presenting in childhood. J Pediatr Gastroenterol Nutr. 2015; 61(3):346-54.

5. Lee W, Wong S, Ivy D, SokolR. Hepatopulmonary syndrome and portopulmonary hypertension in children: recent advances in diagnosis and management. J Pediatr. 2018; 196:14-21.e1.

6. Raevens S, Colle I. Hepatopulmonary Syndrome and Portopulmonary Hypertension. In Muriel P (ed). Liver Pathophysiology: Therapies and Antioxidants. London: Elsevier; 2017.Págs.517-22. 
7. Sokol R. Portopulmonary hypertension: opportunities for precision pediatrics. J Pediatr Gastroenterol Nutr. 2015; 61(3):268-9.

8. ErikssonC,GustavssonA,KronvallT,TyskC.Hepatotoxicity by bosentan in a patient with portopulmonary hypertension: a case-report and review of the literature. J Gastrointestin Liver Dis. 2011; 20(1):77-80.

9. Krowka M, Fallon M, Mulligan D, Gish R. Model for endstage liver disease (MELD) exception for portopulmonary hypertension. Liver Transpl. 2006; 12(Suppl 3):S114-6.
10. Ramsay M. Portopulmonary hypertension and right heart failure in patients with cirrhosis. Curr Opin Anaesthesiol. 2010; 23(2):145-50

11. Laving A, Khanna A, Rubin L, Ing F, et al. Successful liver transplantation in a child with severe portopulmonary hypertension treated with epoprostenol. J Pediatr Gastroenterol Nutr. 2005; 41(4):466-8.

12. Salgia R, Goodrich N, Simpson H, Merlon R, Sharma P. Outcomes of liver transplantation for porto-pulmonary hypertension in model for end-stage liver disease era. Dig Dis Sc. 2014; 59(8):1976-82. 